\title{
A FINNISH ROAD DESIGN COMPETITION BASED ON THE SERVICE LEVEL METHOD
}

\author{
MATTI KILJUNEN \\ Southwestern Finland ELY Centre, Transport and Infrastructure, Finland
}

\begin{abstract}
As a comprehensive approach, the service level concept idea is a method that the Finnish Transport Agency (FTA) has been studying to develop the traffic system design. On an international level, defining and examining the service levels of certain areas, including public transport and congestion, has become routine. However, examining the entire traffic system using the service level concept is a brand new area. Several studies and reports have been commissioned on the service level method but there continues to be a need to bring it closer to the practical design process. As part of the development of transport planning, FTA organised a design competition in 2014-2015. The competition assignment involved the definition of different elements of the service level and related emphases. The competition acted as a "road test" aiming to experiment with the effectiveness of a number of new design theories as well as the new methods for the commissioning/procurement of design. The design subject was the 140 kilometres Turku-Pori section of Highway 8 on the coast of the Baltic Sea. The section is considered to have multiple problems. Based on the results of the competition, it appears that the service level method is a suitable starting point and working approach for transport planning, but certain development needs and shortcomings were also detected. The service level-based design appears to be useful as a procurement procedure used by the public sector. Nevertheless, on the whole, the modes of transport with established definitions for service levels, such as road traffic and public transport, were highlighted. Thus far, no theoretical basis exists for the service level of walking and cycling, which resulted in their more superficial examination. The results of the competition were utilised in further planning of the section.

Keywords: service level method, transport planning, design competition, service level objectives, traffic system design, trip chain, commissioning and procurement methods.
\end{abstract}

\section{INTRODUCTION}

\subsection{Part of the design development programme of the Finnish Transport Agency}

In Finland, the Finnish Transport Agency (FTA) is responsible for maintaining and developing the state-owned transport network. The regional organisations operating under the Finnish Transport Agency are responsible for around 75,000 km of roads, $6,000 \mathrm{~km}$ of railway network and Finland's waterways. In turn, FTA operates under the administrative branch of the Ministry of Transport and Communications [1].

In Europe, the administrative structures in the transport sector are undergoing changes. Since 2010, the traffic administration of Finland has also aimed to develop new operating models as well as design the traffic system as a whole. There is need for reform in four segments, including [2]:

- $\quad$ transport and community planning

- financing of the traffic system and charges for its use

- procurement of the service level and

- service production 
This new form of thinking shifts the focus of policy-making from individual projects to defining the service level produced with public funding. The implementation of the service level will utilise different methods and technology diversely. According to a report completed in 2011, no similar entity reforming the entire way of thinking and operating models has been implemented in Europe or anywhere else in the world [2].

Perspectives related to the reform include [2], [3];

1. the service level method.

2. the so-called Swedish four-step principle.

3. the simultaneous examination of land use, dwelling, transport, service structure and businesses.

4. the trip chain approach applied to both passenger as well as goods transport.

The structures of any given society are bound to change. Significant changes will occur in industrial structures, in the population's dependency ratio, due to urbanisation as well as the introduction of intelligent technology. In the Finnish transport policy, these changes have provided a starting point for a reform of the structures and operating practices of design and planning. For instance, experimentation is used to explore novel and more efficient operating practices [4].

Reports, seminars and studies had focused on the service level method for two years when it was decided that it was time to take the idea out of the laboratory and into testing. At the beginning of 2014, the Finnish Transport Agency assigned a regional state authority, namely the Southwestern Finland ELY Centre, with the task of organising a service levelbased design competition targeting the Turku-Pori section of Highway 8. [5] It was time for a road test.

\subsection{The theoretical foundations of the service level method}

The service level orientation puts emphasis on the task of pre-planning at the traffic system level to target and set objectives for more detailed planning as well as the importance of cooperation and commitment of different parties, and a user-oriented approach. In Finland, the public sector is generally responsible for a traffic system operating in line with needs and demands; however, it is not required to produce all services. The aim of service level-oriented design is that the contents of design are more strongly guided by the objectives derived from user needs [4].

In the context of traffic, the service level method is a familiar and widely used concept in public transport, describing and predicting the qualities of traffic flow, for example in the Highway Capacity Manual [6], as well as in the winter maintenance of the transport network. The concept has been used to describe system functionality in a number of other fields, such as telecommunications.

However, using the service level concept as a method for examining the transport network as an entirety is new [2].

Within the general framework of transport policy, the key objective of the service level oriented approach is to have the pre-planning process begin by analysing the related needs and desired impacts. At this stage, decisions on the desired travel and transport service level are not yet binding and will not limit the final solutions. A service level-oriented approach underscores the objective of pre-planning at transport system level, in order to provide a direction and set goals for more detailed planning work. 


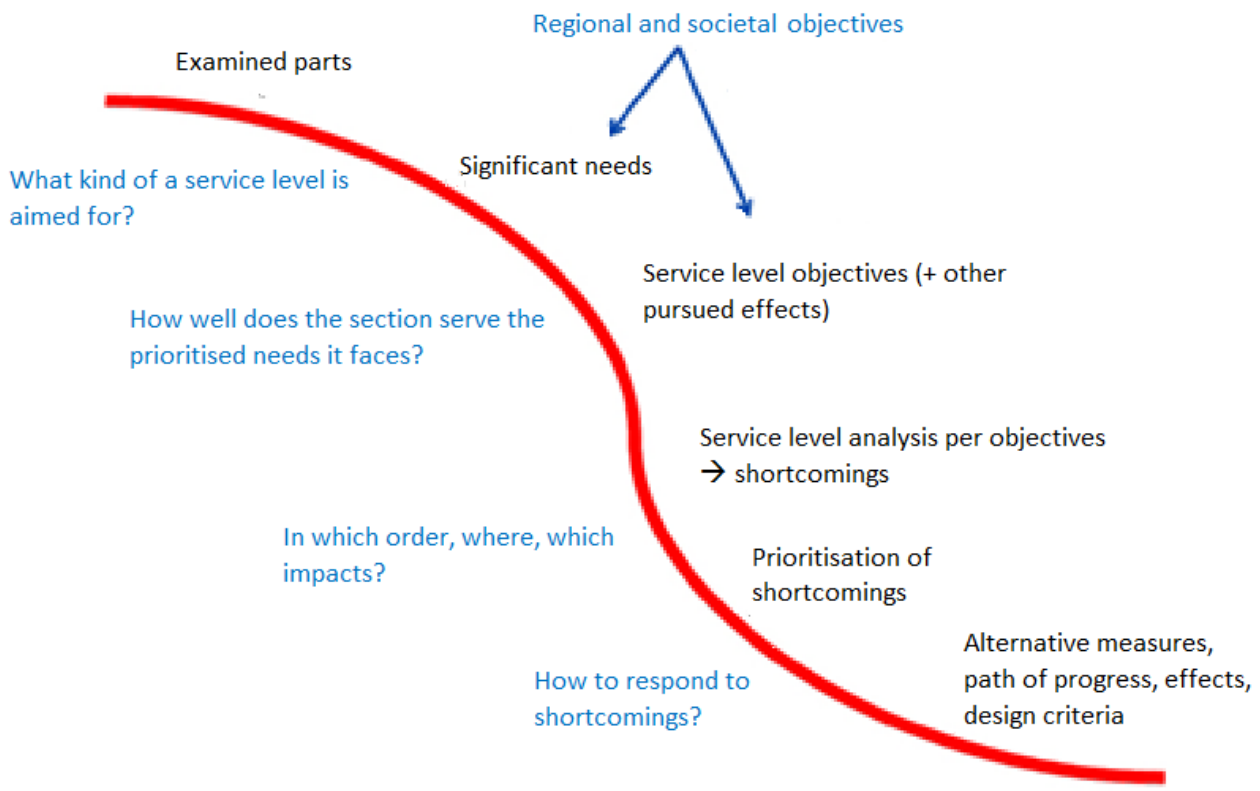

Figure 1: The "red thread" running through the design of a transport section [4].

Similarly, such an approach emphasises the importance of a focus on the user and of cooperation and commitment between the various parties involved in the planning process. [4].

In Finland, the Finnish Transport Agency has shown an interest in renewing the principles of developing the transport network. The government would like to purchase a higher service level instead of focusing on individual investments [4].

\subsection{Trip chain approach}

The Finnish Transport Agency has shown an interest in focusing particular attention to developing the trip chains for long-distance passenger and goods traffic. According to the Nordic trip chain studies, a trip chain approach improves the competitiveness of public transport, accessibility and node functionality. The trip chain approach has highlighted the need to deepen the understanding of user needs and therefore new methods for data collection and transport modelling have been developed. The trip chain approach puts the transport system users and their needs in the centre of the planning. The most critical factors of trip chaining are the chain speed, the fluency of the interchanges, disturbance sensitivity and the pedestrian and bicycle traffic conditions. [7].

\subsection{The Swedish four-step principle}

The four-step principle is the multi-modal analysis tool utilised in Sweden and Finland to analyse transport related issues. The four-step principle is based on an overall transport mode approach in a multi-modal sense, but in the first hand the principle seeks to handle shortcomings and problems within the road transport. However, the basic idea is that action 
outside the road transport can reduce the need of the particular road and consequently, reduce the need for action concerning the road in question. The principle is initially developed by the former Swedish Road Administration (SRA), i.e. Vägverket [8].

\subsection{Coordination of land use, dwelling, transport, service structure and businesses.}

The method of aiming to integrate the operational precondition of land use, dwelling, transport, service structure and businesses ("MALPE") has potential for promoting the uniform planning of the functional urban region. In particular, coordinating the main outlines of land use and transport planning at the regional level is meaningful. One main strength of the method of promoting uniform planning of land use, dwelling, transport, service structure and businesses is the coordination of the implementation schedules of various measures of executing the plan. However, the method of uniform urban planning requires further development, in particular in strengthening the commitment of the parties involved in the common objectives and measures. In addition, developing methods to implement regional plans on lower levels of the urban planning hierarchy is one of the main targets for further research. Furthermore, to achieve design integration, it is necessary that all related parties have strong enough incentives and interests to develop and promote the common plan. According to the current planning system and legislation this method of uniform urban design and its process are already furthering the uniform design of urban planning entities, as well as contributing to the realisation of the uniform regional plans [9].

\subsection{Development zone planning}

The search for new ways to explore developing the main road network of Finland began around 2010. Between 1997-2010, the observation of the transport network was focused on traffic system design examining regions and employment areas. At the national level, the aim was to recognize and repair the most significant shortcomings in the road and railway networks. During the period, the fragmented administration, for instance the division of regions and the regional division of governmental authorities, might have made it difficult to examine the transport network as a whole. In the $2010 \mathrm{~s}$, there has been a desire to enhance the efficiency of measures and investments. A new examination approach involves perceiving the traffic corridors between larger cities as entities. This has been done to avoid the influence of regions or regional state administrative authorities on the examination principles. The purpose is also to pay more attention to the supraregional trip and transport chains significant for the state. The Transport Revolution project of the Finnish Transport Agency included commissioning a number of reports, trials and pilot projects on the methods of development zone planning [10].

\section{THE DESIGN COMPETITION AS A TEST FOR A NEW PLANNING APPROACH}

\subsection{Part of the design development programme}

The competition was organised as part of the design development programme of the Finnish Transport Agency (FTA). Transport planning is often criticised for being stuck in predictions, norms and passenger-vehicle-centred thinking. The aim of the competition was to test the service level method, trip chain examination, the four-step principle as well as the coordination of land use, dwelling, transport, service structure and businesses in the context of development zone planning. The competition for ideas for Highway 8 was a novel 
experiment from the viewpoints of the design subject, its mission as well as further work on the topic [5].

The road section selected as the design subject is exceptionally long. This is the 140 kilometres Turku-Pori section of Highway 8, a passage with multiple problems. Numerous planning phases had been prepared for the section, but the cost estimates had already previously been considered too high in relation to the possibilities for their implementation, and the plans were projected to be partly outdated [5].

As such , utilising the service level method in urban planning is not a novel idea. For instance, architectural competitions have traditionally been "service level-oriented" in that the competition assignments outline requirements not only for the settings but also for the gross floor area, number of inhabitants and parking spaces in the new area.

\subsection{The starting point of the $140-\mathrm{km}$ section with multiple problems}

The scope of the Finnish highway network is around 8,600 km. Only $13 \%$ are dual carriageways. The road network, constructed mainly in the 1960s and 1970s, is relatively narrow and there is plenty to improve in the intersections. Improving such a network is expensive and, therefore, different alternatives for measures are regularly evaluated.

The problems of the Turku-Pori section of Highway 8 are typical for a Finnish dual carriageway section [5]:

- Safety deficiencies

- Congestion

- Problems in intersections

- Land use is stuck due to the road

- The breakthrough of public transport

- Difficulties in transport

- Shortcomings in pedestrian traffic and cycling

- Needs to protect the environment

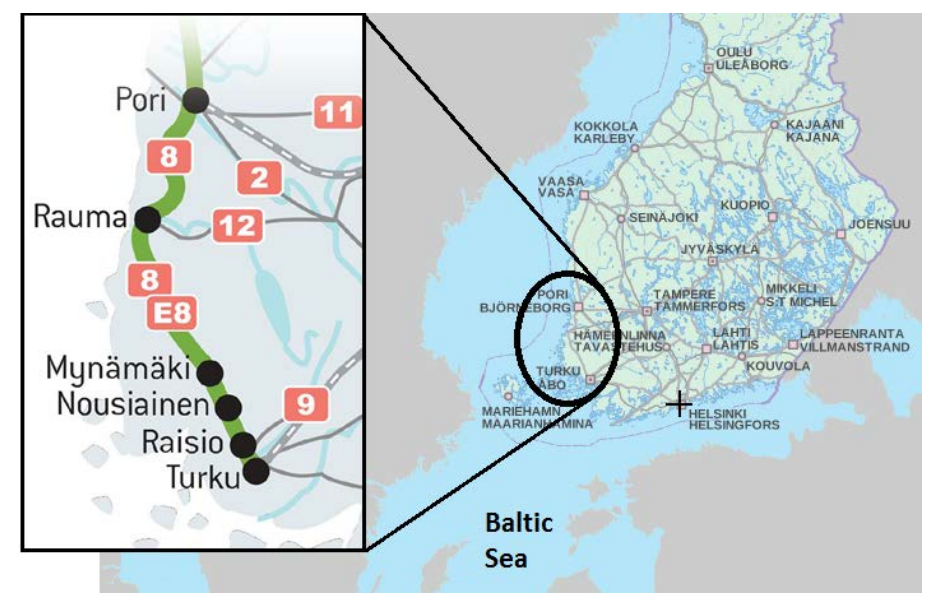

Figure 2: The Highway 8 in Southwest Finland. Map: National Land Survey of Finland. 


\subsection{Setting the emphases for the objectives}

The service level method was determined as the principle for organising the competition already in the assignment description prepared by the Finnish Transport Agency. The general objectives and principles and the majority of the service level objectives had been adopted nearly in their original form from the traffic system design for Satakunta and the traffic strategy of Southwest Finland approved by the regional governments. With the management of the preparatory group of the competition, the objectives were worked on and fleshed out to the form applied in the pre-planning competition [5].

The aim was for the service level objectives and emphases of the Highway 8 design competition to dispense with the Highway Capacity Manual type idea concerned solely with the flow of road traffic. The emphases of the main groups of the objectives were as follows [5]:

- $\quad$ Traffic safety (emphasis $30 \%)$

- Transports $(25 \%)$

- Environment and land use (15\%)

- Trips taken without a passenger car $(15 \%)$

- Trips taken with a passenger car (15\%)

A broad selection of issues was presented for the participants' consideration: physical solutions, administrative solutions, design methods, level of costs, and the path of progress. The old plans were naturally not abandoned; instead, they were included in the background material. Extensive background material on transport and land use was compiled for the use of the contestants, but they also had to analyse the shortcomings of the area as well as relevant needs.

The organisers knew that the workload caused by the arrangements for the competition was significant. Therefore, a competition secretary was hired [5].

\subsection{Technical arrangements for the competition}

The competition followed the provisions of the Finnish Act on Public Contracts. The competition was announced in a timely manner on the website for the public procurements in Finland. An event for presenting the competition was organised when the competition was launched. As with all public calls for tenders, those interested in submitting their ideas could ask questions at this point [5].

At the enrolment phase, seven companies or joint ventures submitted their applications to participate. The references of personnel and the work programme outlined in the application were scored. Each group selected for the competition was required to include a land use planning professional. The working groups of each of the applicants included experts with traditional competence on road, traffic and urban planning. Based on the rules for design contests, four working groups were selected into the actual competition. In order to safeguard the secrecy of the competition, the people responsible for scoring the applications at the first phase and making the selection on the participants did not act as voting members of the jury at the second phase. It was not even revealed to the jury and competitors at the second phase which working groups had been selected to the competition. At the competition phase, the participants could ask questions from the jury via the competition secrecy, which helped ensure anonymity [5]. 
The envelopes with names were not opened until the competition's awards ceremony. Therefore, the participants did not know who would win prior to the event. Everyone involved found the arrangements somewhat stressful; however, the measures guaranteed the transparency of judging of the competition. The winner, which had participated in the competition under the alias "HOTPOT", was Ramboll Finland Oy with Riikka Salli, M.Sc. (Tech.) as the Project Manager [11].

\section{CONTRIBUTIONS TO THE COMPETITION}

\subsection{General features of the entries}

The trip chain approach was apparent in all of the work submitted to the competition and a lot of the generated ideas were related to the approach. The effects of coordination of land use, dwelling, transport, service structure and businesses as well as productivity-pyramidlike examination could also be seen in the projects. Nevertheless, the final results differed from one another, which means that the pre-determined service level objectives, although fairly detailed, did not restrict the measures selected by the competitors. Each of the entries had their own approaches and emphases for developing the Highway 8 section. Impact assessment was realised, and reasoning were given to it, in different ways in the competition entries. The entries were carefully constructed and did not appear to be put together at the last minute. Certain parts indicated that the groups had been in a hurry, which implied that the groups had struggled with scheduling [11], [13].

\subsection{Feedback on the competition}

As part of the competition arrangements, feedback was collected from the participants after they had submitted their work, and from the jury after the results had been made public. A separate learning report was compiled of the work. Based on the feedback [12].

a) The responses by the participants and the jury indicated that organising the competition in two phases and under aliases was perceived well.

b) Using the service level method as the starting point for the competition was considered to work well, although some development needs were also detected and some responses also disagreed with this view.

c) From the viewpoint of the four participating teams, the competition had offered a refreshingly novel way for seeking new ideas. There was a lot to be done, which meant that the working groups had to prepare timetables and carefully organise their work.

d) According to the views of the jury, the work was relatively innovative, but there was room for improvement in the overall quality. At the enrolment phase, the groups had been required to have a broad-based personnel; however, this versatility was not apparent in all of the groups' output.

e) There was a lack of consensus in the jury's feedback regarding whether the competition had brought new aspects to developing the section. Some groups had put more effort in the analysis phase than in the design.

f) The opinions of the jury were split on the usefulness of the service level method.

g) The jury also found that some of the work indicated lack of experience in competitions. The participants sometimes failed at highlighting ideas, even good ones. The jury considered that the lack of experience in competition was manifested as some participants' blandness or disappearance of ideas into the text. 
h) The timetable for drafting the competition proposal was considered strict. For other parts, the arrangements were perceived to be moderately successful.

i) The jury felt that the requirements set for the groups participating in the competition on versatile personnel, work programme and quality plan had enhanced the quality of the work.

j) The results included versatile ideas utilising intersection solutions, land use and new technology, such as digitalisation.

k) Gamification of design had been brought up, which was new in 2014. (Since then, this has been developed further in Finland).

1) In addition to a thorough approach, using a "narrative" method and finding a sensible development path could be considered as the merits of the winner.

\subsection{Evaluation of the theoretical foundation and methods of the service levels}

The competition entries clearly differed in terms of how the objectives appeared to have guided the contents of the proposal. In the best case, the competitors had taken the service level objectives and related emphases into account in the prioritisation of problems and measures and the effect of the objectives was apparent in the contents of the programmes of measures. At worst, there was disconnection between the choices made and the service levels presented in the assignment [12].

The work submitted to the competition varied fairly notably, particularly regarding the methods used to analyse the effectiveness of the measures in relation to the given service level objectives. In two of the best entries, the service level was approached analytically throughout the work by assessing needs, measures and impacts in relation to the objectives [12].

So far, there are no methods for describing pedestrian traffic and cycling at the traffic system level. The competition entries reflected this to a degree, as light traffic played a notably minor role in them. In transport planning, there is long experience of examining the service levels in public transport as well as HCM-based service level examination of the capacity of vehicle traffic. As a result, these two areas were quite carefully considered in all of the entries. Even though land use had been determined as one of the elements of service levels in the competition assignment, examining the topic was left up to the proficiency of the planning officers rather than service level-based analysis and examination, possibly due to a shortage of resources. However, linking it to the development of public transport was apparent in the work [12].

The feedback on the competition revealed that the competitors had hoped that the service level objectives would have been determined in an interaction between different parties before the competition, as is the case with typical (Finnish) planning projects. However, there had been interaction in determining the service level objectives before the competition as part of the preparation of plans for regional traffic systems. Nevertheless, the role of service level objectives has traditionally been overshadowed by the programmes of measures in regional traffic system design. Therefore, as part of the competition preparations, it might have been appropriate to work on the objectives, for instance, in a workshop for local operators, which would have also allowed engaging consultants interested in the participation phase [12].

In addition to the variation in the methods and indicators of impact assessment in the solutions, the cost estimates included in the entries also varied, sometimes also including implausible features. As a result, it was not possible to rank the entries by order of merit 
solely based on the impact and cost effectiveness of the programmes of measures presented in the work, which was the original intention [13].

However, the entries were notably consistent in recognising the worst problem areas. The development ideas presented for some of the most significant problem sites were similarly consistent. This made it easier to continue with further planning after the competition [13].

\subsection{Further work launched immediately after the competition}

Further work was launched one month after the publication of the results at a seminar for stakeholders, which included representatives of the municipalities, chambers of commerce, transport providers and regional councils in the section area. The further work was based on the best ideas picked from all of the proposals submitted to the competition. The further work included specification of the objectives, impact assessment and comparison of the measures by different stakeholders. The projects were examined in relation to the service level objectives and cost effectiveness [14].

The main emphasis of the further work was on determining the measures for the following ten-year period. The impact assessment produced in the competition could be applied and further refined in the work. The impact assessment method put emphasis on intersection sites with multiple problems. Therefore, the used impact assessment paid more attention to, for instance, the impacts of the measures on the development of land use, compared to previous work. Developing electronic availability and public transport stops was also recommended based on the work [14].

\section{SUMMARY AND CONCLUSIONS}

\subsection{Successful features}

- The competition was able to achieve diverse testing the procurement of service level-based design and generating ideas for its development.

- The work was primarily successful in examining the extensive design subject in a service level-oriented way, taking into account all modes of transport (passenger car, public transport, walking, cycling, safety). However, no theoretical background exists for (low-volume) walking and cycling, which resulted in ignoring these topics to an extent. Or the existing models are too difficult to use.

- The "red thread" of service level-based design is successful in terms of the planning hierarchy when the objectives determined in plans at the traffic system level are applied as the starting point for plans at the section level. If there are no up-to-date traffic system plans, the preparation phase should include more extensive dialogue to determine the objectives, for instance, by employing a traffic system working group.

- The service level objectives can be used to direct the planning to outline solutions to the desired objectives.

- The so-called Swedish four-step principle and the trip chain approach had been taken into account quite well in all of the entries. The participants were familiar with these theoretical models and both approaches had been highlighted in design requirements for a few years. 
4.2 The following was learned about service level-based procurement

The area defined for the design competition $(140 \mathrm{~km})$ was apparently too extensive, resulting in the competitors somewhat failing to examine it as a whole. The service level-oriented approach is probably better suited for planning or procurements aimed at a certain, more clearly defined site. The coordination of land use, dwelling, transport, service structure and businesses was apparent in the entries, particularly as the examination of urban centre structures in urban areas. However, due to the extent of the area, the examination of land use was analysis-oriented and the amount of more detailed ideas related to urban planning was fairly low.

In addition to ideas, the service level-based competition also produced problem analyses and new perspectives. Despite having the same objectives, the four competition entries were far from uniform; instead, their emphases and development strategies were clearly different. However, the entries were notably consistent in recognising the worst problem areas. The development ideas presented for some of the most significant problem sites were similarly consistent.

\section{REFERENCE}

[1] https://en.wikipedia.org/wiki/Finnish_Transport_Agency. Accessed on: 27 Feb. 2017.

[2] Tuominen, A. \& Kanner, H., Transport revolution - international perspectives. Publications of the Ministry of Transport and Communications. Helsinki, 19 pp.,2011.

[3] Hakamäki, A., Searching for uniform urban planning - Method of promoting uniform planning of land use, dwelling, transport, service structure and businesses in regional planning. Finnish Transport Agency, Transport and Land Use. Research reports of the Finnish Transport Agency. Helsinki, 188 pp., 2015.

[4] Metsäranta, H., Launonen, P., Savolainen, M., Somerpalo, S. \& Kivari M., Focus on service levels in pre-planning at transport system level. Research reports of the Finnish Transport Agency. Helsinki, 40 pp., 2014.

[5] Southwestern Finland ELY Centre and Finnish Transport Agency 2014. Highway 8 Turku-Pori Competition - Rules and assignment. 221,13 pp., 2014.

[6] The Transport Research Board Highway Capacity Manual. 5th ed. Washington D.C. 1650 pp., 2010.

[7] Rundell E., Trip chains in the transport system planning process. Master's thesis. Aalto University, School of Engineering, Helsinki, 80 pp., 2013.

[8] Poskiparta, L., Collaborative Dialogues in Strategic Multi-Modal Studies - New Tool for Exploring Efficient Solutions in Transport Planning Experiences from the Swedish and the Finnish Contexts. Master's thesis. Kungliga Tekniska Högskolan. Stockholm, 87 pp., 2013.

[9] Hakamäki, A., Searching for uniform urban planning - Method of promoting uniform planning of land use, dwelling, transport, service structure and businesses in regional planning. Aalto University, master's thesis. Finnish Transport Agency Publications /2015. Helsinki, 23, 188 pp., 2015.

[10] Iikkanen, P. et al., Level of service in travel and transport chains. Research reports of the Finnish Transport Agency, Helsinki. 7, 42 pp., 2012.

[11] Southwestern Finland ELY Centre (1). Highway 8 competition, Jury Transcript. Turku. 221, 8 pp., 2015.

[12] Metsäranta Heikki, 2015. Memorandum. Highway 8 competition - Lessons learned. Turku, 15 pp., 2015 
[13] Southwestern Finland ELY Centre (2). Highway 8 competition - Evaluation report. Journal number 21/2014/VAR. Turku, 21 pp., 2015.

[14] Salli Riikka et al. Highway 8 Turku-Pori, principal plan, the final report. Turku, 32 pp., 2016. 